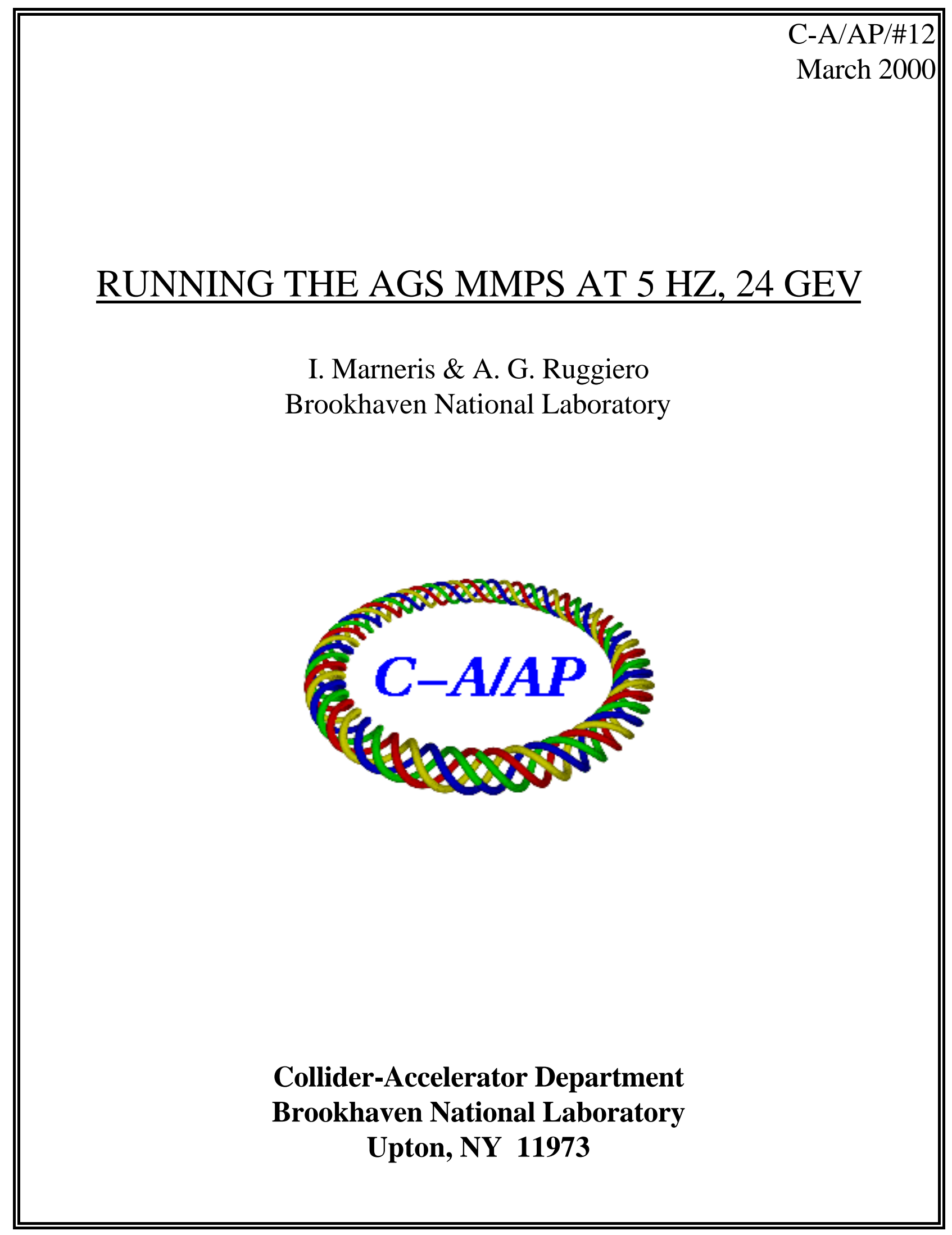




\title{
RUNNING THE AGS MMPS AT 5 HZ, 24 GEV $^{*}$
}

\author{
Ioannis Marneris and Alessandro G. Ruggiero \\ Brookhaven National Laboratory, C-A Department \\ January 21,2000
}

\begin{abstract}
This technical report describes the requirements and the methods to operate the Brookhaven AGS accelerator facility with proton beams at the energy of $24 \mathrm{GeV}$ and the rate of 5 proton beam pulses per second.
\end{abstract}

\section{Introduction}

The Brookhaven Alternating Gradient Synchrotron (AGS) is a strong focusing accelerator, which is used to accelerate protons and various heavy ion species to an equivalent proton energy of $29 \mathrm{GeV}$. Since the late 1960's it has been serving high-energy physics (HEP) users of both slow and fast extracted beams. The AGS fixed-target program presently uses primary proton and heavy ion beams (HIP) in slowly extracted fashion over spill lengths of 1.5 to 4.0 seconds. The AGS is also used as the injector to RHIC.

We are here concerned primarily with the acceleration of intense beams of protons. The typical mode of operation at the present is a proton beam pulse every 1.5-2.0 seconds, if one excludes front-porch and flat-top periods. The top energy is $29 \mathrm{GeV}$ and the maximum intensity achieved is around $7 \times 10^{13}$ protons per pulse. This corresponds to an average beam power of about 0.2 MW. Future programs in high-energy and neutron physics may require an upgrade of the AGS accelerator to a average beam power of around $4 \mathrm{MW}$. This can be achieved with an increase of the beam intensity to $2 \times 10^{14}$ protons per pulse that requires a $1.5-\mathrm{GeV}$ super-conducting linac as a new injector (a subject discussed in a separate paper), and by upgrading the power supply system to allow cycling at 5 beam pulses per second.

This report describes in section 2 the present mode of operation of the AGS power supply, in section 3 the requirements for operation at $5 \mathrm{~Hz}$. The proposed solution is given in section 4. The Motor Generator and Control System are discussed respectively in section 5 and 6 . Finally section 7 discuss briefly other accelerator requirements for the proposed higher repetition rate.

\section{Present Mode of Operation}

The AGS Main Magnet Power Supply (MMPS) is a 6000 Amp, \pm 9000 Volt SCR power supply. A 9-MW Motor Generator, made by Siemens, is a part of the main magnet power supply of the accelerator, which allows to pulse the main magnets up to $50 \mathrm{MW}$ electric

\footnotetext{
* Work performed under the auspices of the US Department of Energy
} 
peak power, while the input power of the motor generator remains constant. The maximum power into the motor ever utilized is $7 \mathrm{MW}$, that is the maximum average power dissipated in the AGS magnets did not ever exceed $5 \mathrm{MW}$.

The AGS ring consists of 240 magnets hooked up in series. The total resistance $\mathrm{R}$ is $0.27 \mathrm{ohm}$ and the total inductance $\mathrm{L}$ is 0.75 henry. There are 12 super-periods, $\mathrm{A}$ through L, of 20 magnets each, divided in two identical sets of 10 magnets per superperiod.

There are two stations of power supplies each capable of delivering up to 4500 Volt and 6000 Amp. The two stations are connected in series as shown in Figure 1, where the two magnet loads have a total resistance $R / 2$ and a total inductance of $L / 2$. The grounding of the power supply is done only in one place, in the middle of station 1 or 2 through a resistive network. With this grounding configuration, the maximum voltage to ground in the magnets will not exceed 2500 Volt. The magnets are hi-potted to 3000 Volt to ground, prior of each starting of the AGS MMPS after long maintenance periods.

Each of the two stations is composed of the F-bank and the P-bank power supplies in parallel. The F-bank power supply consists of 24 pulses (fundamental frequency $1440 \mathrm{~Hz}$ ), \pm 1900 Volt maximum, and $6000 \mathrm{Amp}$, and are used during the flat tops of the AGS cycles. The P-bank power supply consists of 12 pulses (fundamental frequency $720 \mathrm{~Hz}$ ), \pm 9000 Volt, and $6000 \mathrm{Amp}$, and are used during ramping up or down of the AGS cycles. This ensures minimum ripple during the flat tops, an essential condition for slowly extracted beam. However, there were still frequency components multiples of $60 \mathrm{~Hz}$ that needed to be reduced. An active filter was developed to reduce these frequencies. This was done by feeding these frequencies 180 degrees out of phase to a chock connected in series with the magnets of station 1 , and by using a voltage regulated power supply. In addition to the active filter, there are two 300-Hz, 60$\mathrm{dB} /$ decade passive filters to minimize voltage ripple of the AGS MMPS. SCR's and a set of fast and slow 95 switches are used to short stations 1 and 2 in case of a failure of the AGS MMPS, so that the energy stored in the AGS magnets decays with the L/R $=3 \mathrm{~s}$ time constant

Figures 2,3,4 display the magnet current, voltage and instantaneous power of a typical proton pulse. The total cycle period is 3.6 seconds long, including a 1.6-second flat-top and a 0.8 -second front-porch. The acceleration and deceleration ramp lasts 0.6 seconds. At $28 \mathrm{GeV}$ the maximum current is $5.0 \mathrm{kAmp}$, the voltage varies between -5.7 and $6.7 \mathrm{kVolt}$, and the peak power is $35 \mathrm{MWatt}$. The average power dissipated in the AGS magnets for this pulse was calculated to be $3.7 \mathrm{MW}$.

\section{$3 \quad$ 5-HZ Mode of Operation}

To cycle the AGS ring for the $24-\mathrm{GeV}$ proton mode of operation at 5 pulses per second, the magnet peak current is 4300 Amp. Figures 5, 6 and 7 display the magnet current, voltage and instantaneous power of a 4300-Amps 5-Hz cycle. The cycle does not include a front-porch and a flat-top. Only single-turn fast-extraction has been assumed. The magnet ramp, up and down, takes 0.1 second. The total average power dissipated in the AGS magnets has been estimated to be $1.7 \mathrm{MW}$.

Figure 6 shows that one needs $\pm 30 \mathrm{kVolt}$ across the whole magnet system It was mentioned in section 2 that currently the maximum voltage to ground, the magnets see, is 
2500 Volt maximum. Assuming that we are not going to redesign the AGS magnets, this constrain has to be followed in the new design of the AGS MMPS to run at $5 \mathrm{~Hz}$.

\section{$4 \quad$ Proposed Solution}

A possible solution is to divide the AGS magnets in four identical sections, and run every quarter section separately with an identical system of power supplies, as shown in Figure 8. It is assumed that the existing ripple specifications are to be preserved, and to be able to run PPM modes. This means that super-period A and half of super-period B should be connected to station-1 power supply, while super-period $C$ and the other half of superperiod B are connected to station-2 power supply, in the fashion similar to the one presently used. The total voltage that super-periods $\mathrm{A}, \mathrm{B}$ and $\mathrm{C}$ would experience is $1 / 4$ of the $\pm 30 \mathrm{kVolt}$, that is \pm 7500 Volt. As a result, every magnet would still see not more than the specified 2500 Volt to ground. In a similar manner superperiods D, E and F would be connected to another identical system of power supply. Also super-periods $G$, $\mathrm{H}$ and $\mathrm{I}$ and super-periods $\mathrm{J}, \mathrm{K}$ and $\mathrm{L}$ would be connected to identical systems of power supply.

A block diagram of an individual power supply system, connected to one quarter of the AGS ring, is still equivalent to the one shown in Figure 1, except that now the magnet loads is $1 / 8$ of the total resistance and inductance. A total of four of such power supply systems are thus required.

\section{The Motor Generator}

As one can see from Figure 7, the peak power required is approximately $130 \mathrm{MW}$. The existing motor generator cannot provide such a power swing, since it is rated at only 50 MW. One needs to investigate if the upgrade can be done with a 200-MW generator or perhaps two 100-MW generators. It is convenient and maybe more economical that the motor generator(s) is of 6 or 12 phase to limit or even eliminate phase-shifting transformers so that every power supply system generates 24 pulses. The generator voltage would have to be around $30 \mathrm{kVolt}$ line-to-line, for the case of a single generator. In this case the generator current is approximately equal to the magnet current during the time that the P-banks are turned on, as it is presently done. If however two 100-MW generators are used, the output voltage would have to be $15 \mathrm{kVolt}$ line-to-line. An other specification of the motor generator is the $5 \mathrm{~Hz}$ frequency. That is, the generator is to be rated at a slip frequency of $5 \mathrm{HZ}$. Clearly one needs to investigate what is available in the market, regarding these specifications as far as a motor generator is concerned, and costs involved. Another approach is to use the existing motor generator and the rest of the power system for one quarter of the AGS ring, provided that it can indeed run at $5 \mathrm{HZ}$, and use another motor generator rated at $150 \mathrm{MW}$ with a voltage $24 \mathrm{kV}$ line-to-line, for the other three quarters of the AGS ring.

\section{Control System}

The control system of each quarter of the AGS ring upgraded power supply is exactly the same as the existing control system for the MMPS. There will be a voltage regulator for 
the following pairs of power supplies, (one for every pair, with reference to Figure 1): Mod. 1 and Mod. 2, Mod. 3 and Mod. 4, Mod. 5 and Mod. 6, Mod. 7 and Mod. 8. There will also be a current regulating system as the outer loop of all four voltage loops. All voltage references would be derived from the same MMPS computer program, except that they will be divided by 4 . However, the current references will be exactly the same as utilized currently. In order to ensure that the currents in all four quarters of the AGS ring are the same, the current loop of one of the four sections will be selected as the master (1), and the other three current loops as the slaves(2, 3 and 4). For instance, the current of section 2 is to be compared to the current of section 1, and the difference added to the current reference of the current loop of section 2. The same principle applies to the current loops of sections 3 and 4. An issue to be studied in more detail is the bandwidth of the current loops. These loops must be 6 times faster than the present one, and a bandwidth of at least 10 to $20 \mathrm{~Hz}$ may be required.

The interlock system of every quarter of the AGS ring power supply system is exactly the same as the existing interlock system for the MMPS, which uses a PLC system. Again one of the PLC systems of the ring would have to be the master and the other three the slaves. It is important that all four power supplies are shut-down together when required for emergency and safety.

\section{$7 \quad$ Other Accelerator Requirements}

\section{Eddy Currents}

Running the AGS at $5 \mathrm{~Hz}$ requires that the acceleration ramp period decreases from 0.6 $\mathrm{sec}$ down to $0.1 \mathrm{sec}$. That is, the magnet current variation $\mathrm{dI} / \mathrm{dt}$ is 6 times larger that the present rate. Eddy-current losses on the vacuum chamber are proportional to the square of $\mathrm{dI} / \mathrm{dt}$, that is 36 time larger than with the present mode of operation. Also, it is expected that the Eddy-current will alter the quantity and the quality of the magnetic field of the magnets during acceleration by 2 to $3 \%$. The increase of the sextupolar field is also a concern for the beam stability that needs to be addressed.

\section{$\underline{\text { Real Estate }}$}

The new motor generators and power supplies are to be housed in new buildings. The motor generators very probably can be located in one central building. But four major power supply utilities are to be located around the periphery of the AGS ring. The construction, acquisition and location of new buildings may be problematic considering the limitation of the available real estate.

\section{The rf System}

Because of the six-fold increase of the acceleration rate, the rf voltage and power will have also to increase maybe as much as by three fold. The most obvious approach is to duplicate twice the present rf system, possibly with more compact cavities, still preserving the same frequency operating at the harmonic number $h=12$. 


\section{$\underline{\text { Injection and Extraction }}$}

Injection is planned at $1.5 \mathrm{GeV}$, the same energy as presently, though with a different type of injector. Fast extraction of a single turn is being proposed at $24 \mathrm{GeV}$. Both injection and extraction components have certainly the required strength; nevertheless, they need now to operate at the rate of five pulses per second. Their capability to perform in this sense has to be reviewed and assessed.

\section{$\underline{\text { Instrumentation }}$}

Beam position monitors and other beam diagnostic devices will have to be reviewed, and their capability to perform at the repetition rate of $5 \mathrm{~Hz}$ will have to be studies. The beam position monitors are of special importance since they are used with steering dipoles in connection of closed orbit correction.

\section{Conclusion}

We have determined, during this preliminary and brief study, that the upgrade of the AGS accelerator facility to operate at the rate of five beam pulses per second is certainly feasible. We have outlined an approach to modify and to add to the present power supply system. One needs to expand and acquire a new motor generator. One needs to divide the AGS magnet ring in four sections each connected to a separate power supply.

We have also reviewed preliminary the performance of other accelerator systems that require attention for the proper operation at the new acceleration rate.

In order to determine the cost of the upgrade and more specifically the details of the upgrade, a conceptual study has to be undertaken lasting a period of few months. 


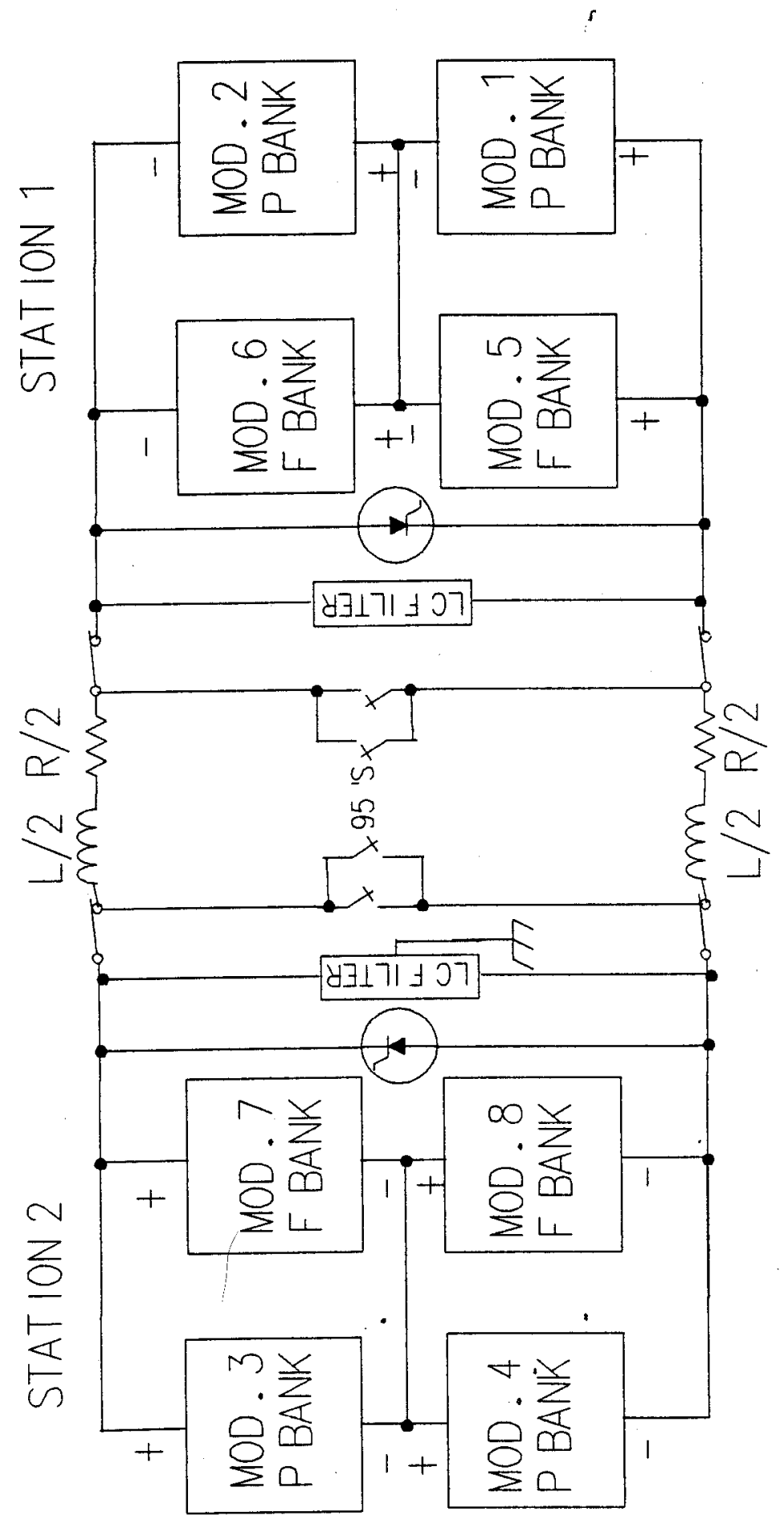

Figure 1. Present AGS Magnet Power Supply Configuration. 


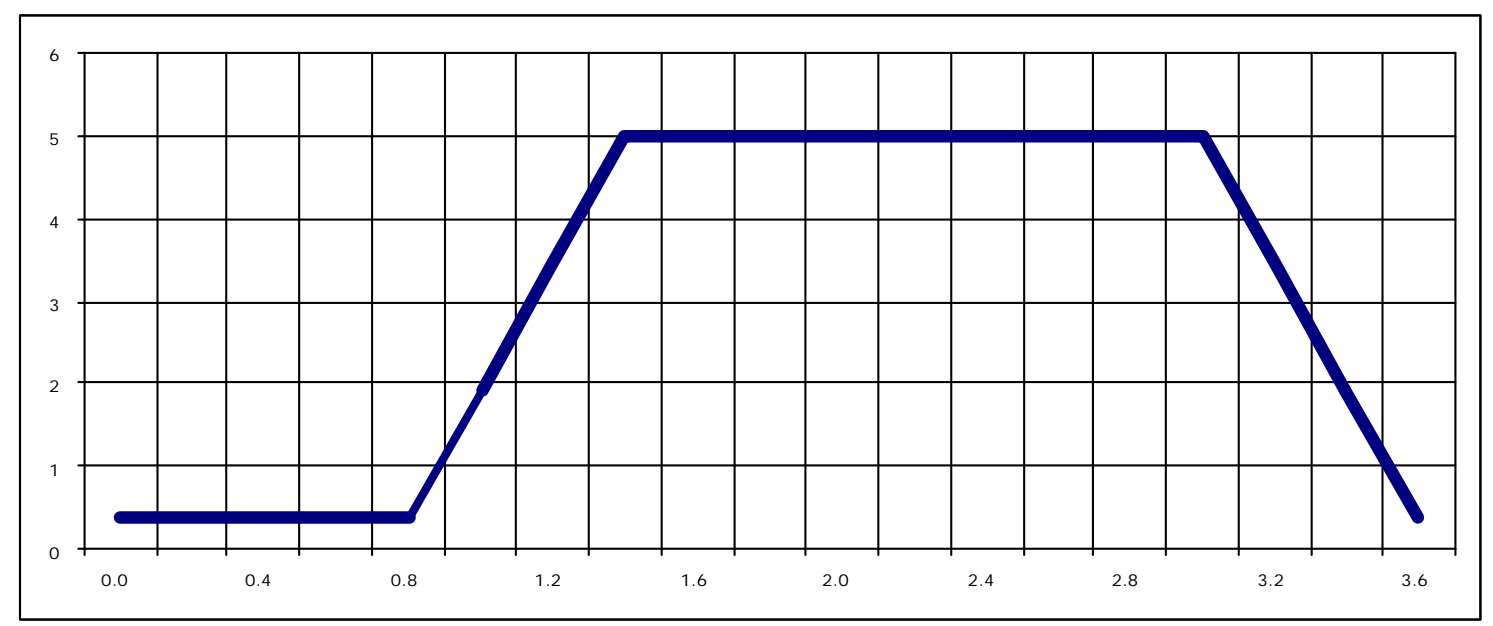

Figure 2. Magnet Current (kA) vs. Acceleration Cycle for present mode of operation.

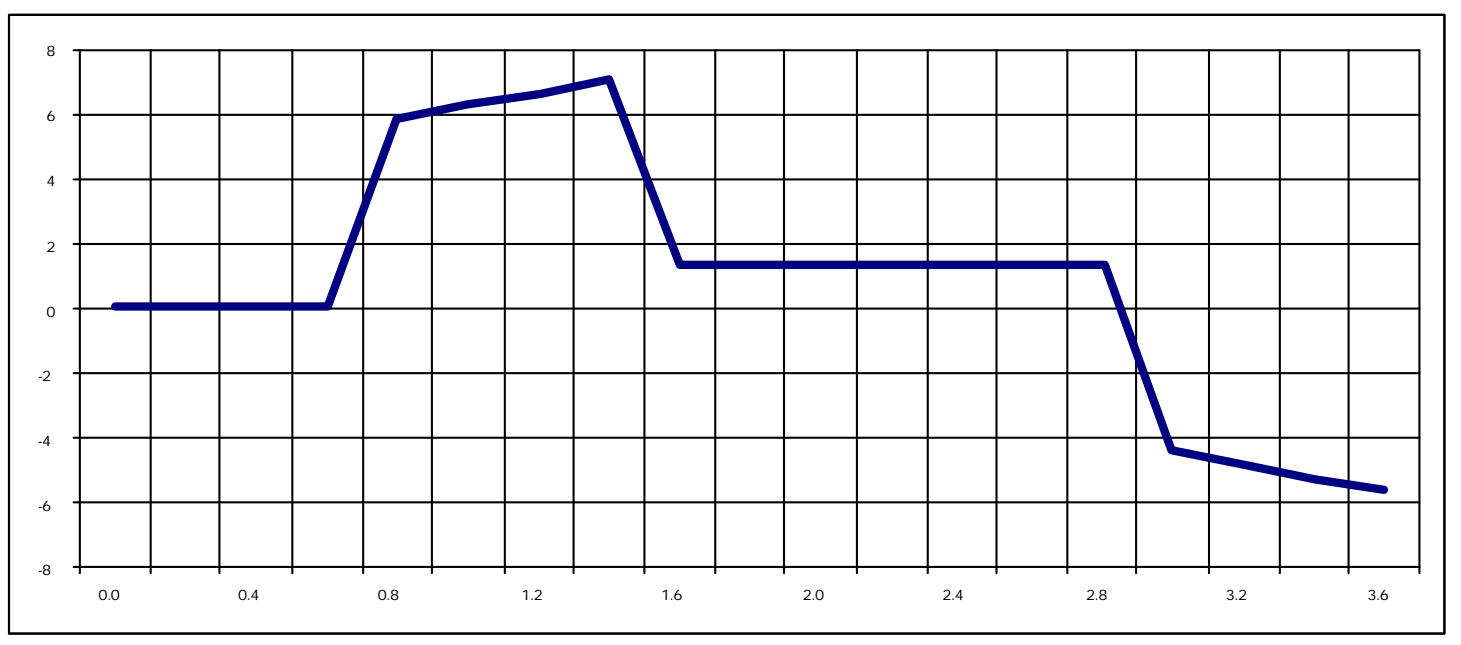

Figure 3. Total Voltage (kV) vs. Acceleration Cycle for present mode of operation.

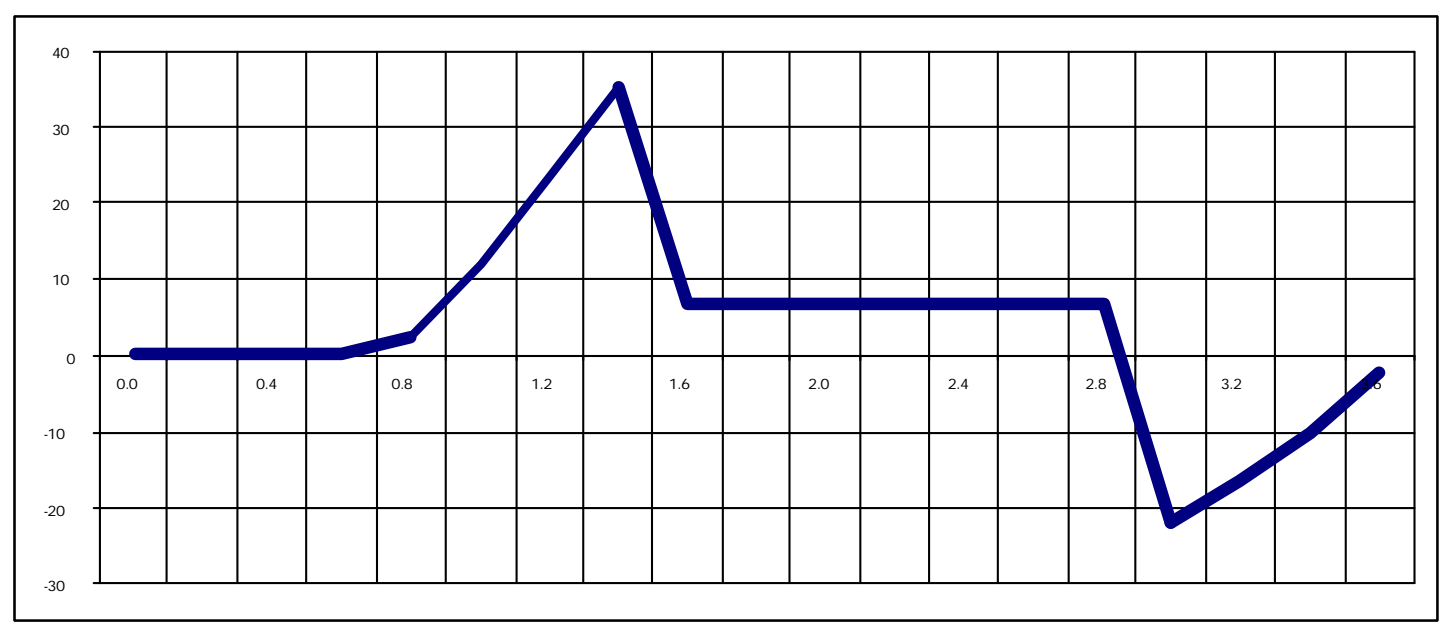

Figure 4. Electrical Power (MW) vs. Acceleration Cycle for present mode of operation. 


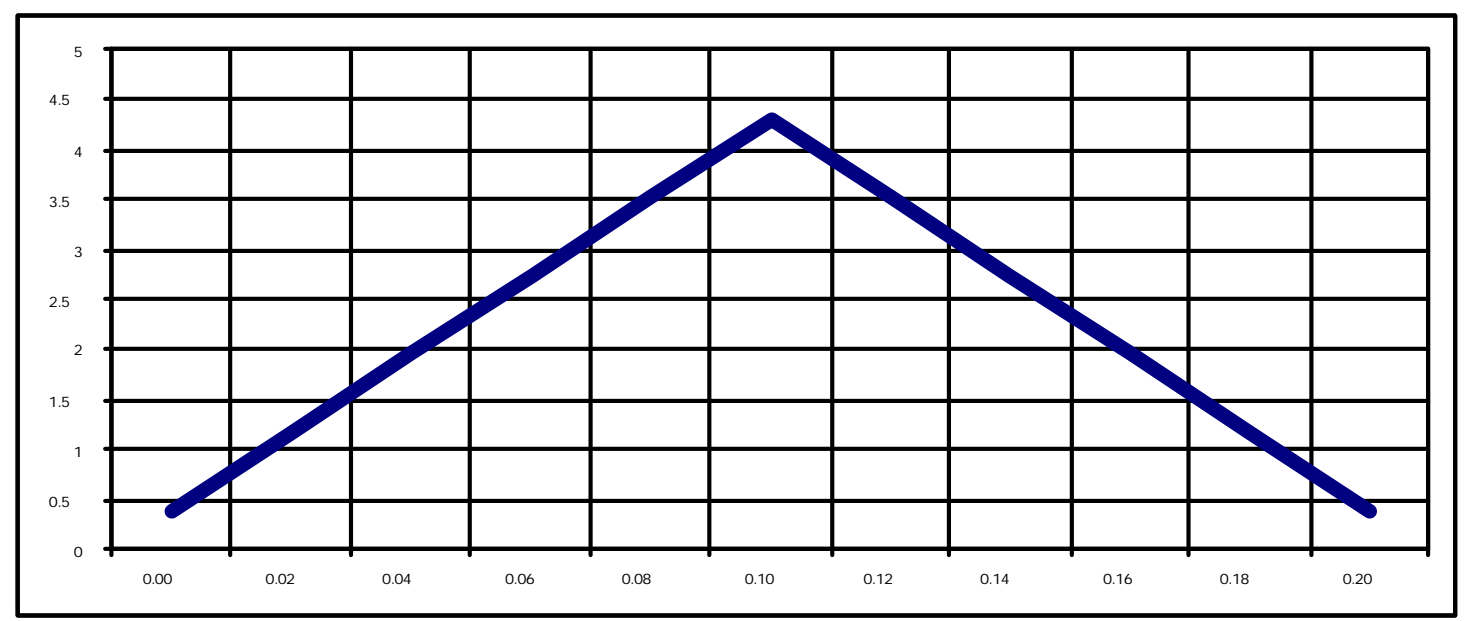

Figure 5. Magnet Current (kA) vs. Acceleration Cycle for the 5-Hz proton operation.

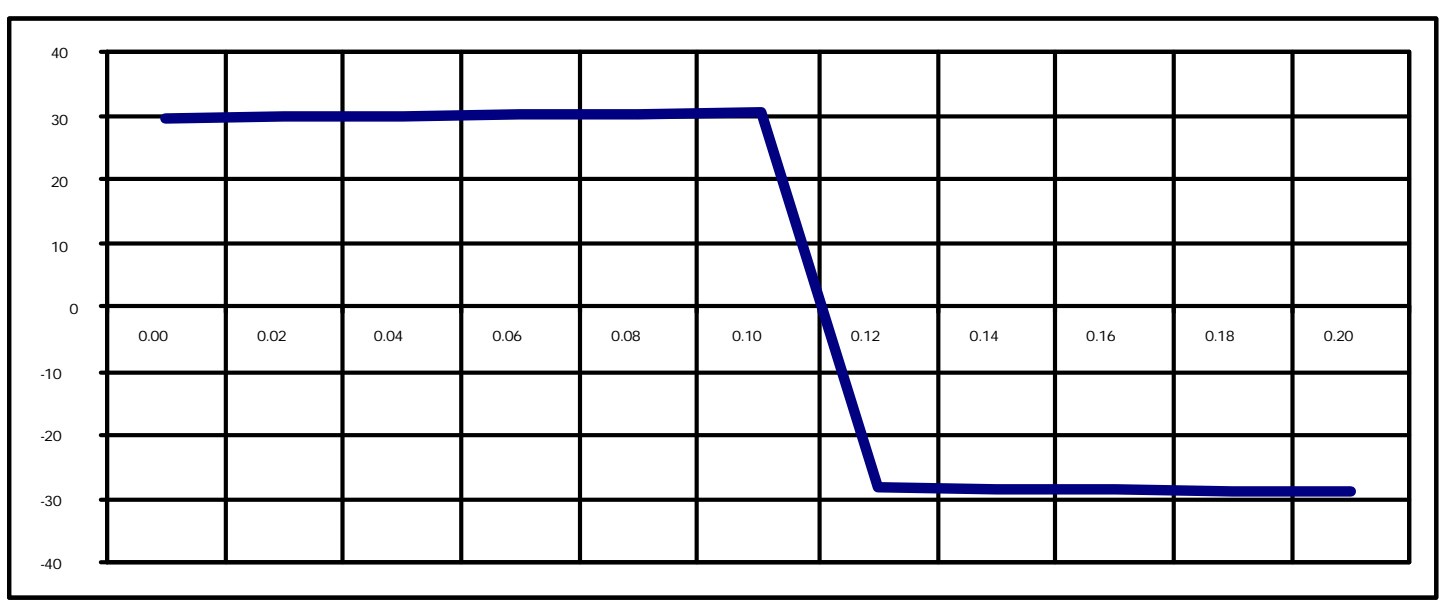

Figure 6. Total Voltage (kV) vs. Acceleration Cycle for the 5-Hz proton operation.

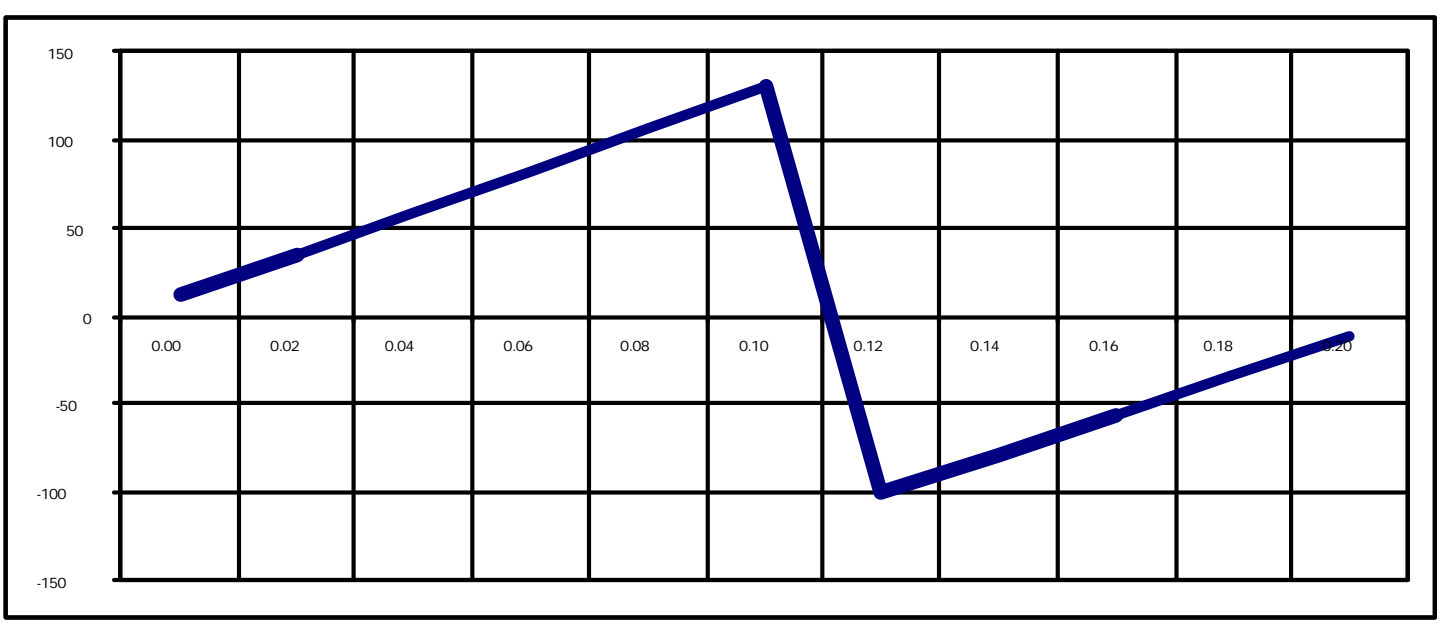

Figure 7. Electrical Power (MW) vs. Acceleration Cycle for the 5-Hz proton operation. 


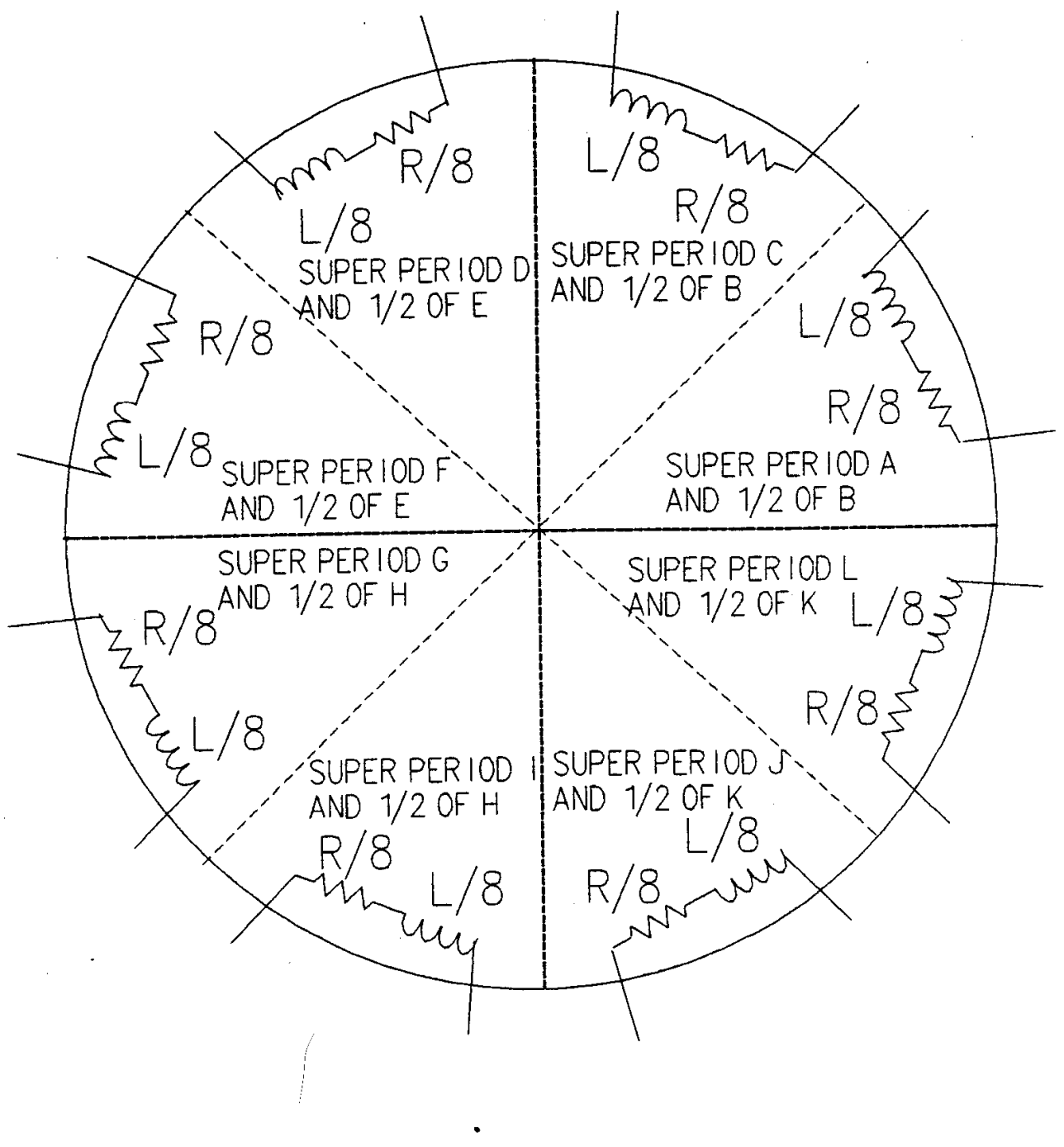

Figure 8. Modified AGS Power Supply Configuration for the 5-Hz mode of operation. 